\title{
Processo de design e avaliação de nudges (estímulos) para redução do abandono escolar entre estudantes com deficiência
}

\author{
Design process and evaluation of nudges (incentives) to reduce school dropout \\ among students with disabilities
}

Cézar Cavalcanti, Débora Vasconcellos, Stéphanie Gomes Medeiros

nudge, design thinking, evasão escolar, pessoa com deficiência

O propósito deste artigo é compartilhar os conhecimentos obtidos através de experimento com nudges (estímulos comportamentais) através de mensagens de texto (SMS) e voz (torpedo de voz), para diminuir a evasão escolar de estudantes com algum tipo de deficiência (PCDs) em transição entre escolas públicas municipais para estaduais da região do agreste pernambucano. Com objetivo de executar o experimento para avaliar a eficácia de mudança de comportamento através dos nudges, foi feito processo de design thinking para construção das estratégias e estímulos, além da operacionalização e posterior avaliação. Aqui apresentamos detalhes e reflexões sobre o processo de design para construção de nudges, reflexões sobre restrições do design da informação nas mensagens usadas, bem como diretrizes para outros experimentos com nudges via mensagens de texto/voz. Apresentamos também o resultado da avaliação quantitativa do experimento que, apesar de denotar efeito positivo (aumento do número de matrículas em cerca de $2 \%$ ) traz resultados inconclusivos por questões amostrais. Além disso, apontamos sugestões emergentes do processo para o desafio complexo da continuidade dos estudos dos estudantes PCD, que notavelmente precisam ir além dos estímulos.

nudge, design thinking, school dropout, people with disabilities

The purpose of this article is to share the knowledge obtained through experimenting with nudges (behavioral incentives) through text messages and voice messages, to reduce the school dropout rate of students with some type of disability in transition between public and municipal public schools in the region of the harsh Pernambuco. In order to carry out the experiment to assess the effectiveness of behavior change through nudges, a design thinking process was carried out to build strategies and stimuli, in addition to operationalization and subsequent evaluation. Here we present details and reflections on the design process for building nudges, reflections on information design restrictions in the messages used, as well as guidelines for other experiments with nudges via text / voice messages. We also present the result of the quantitative evaluation of the experiment, which, despite showing a positive effect (increase in the number of enrollments by about $2 \%$ ), brings inconclusive results for sample reasons. In addition, we point out suggestions emerging from the process for the complex challenge of continuing the studies of students with disabilities, who notably need to go beyond incentives.

\section{Introdução}

De acordo com dados do censo escolar de 2019 realizado pelo INPE, as matrículas de estudantes com necessidades especiais em Pernambuco cresceram 46,3\%. Das 45.643

Anais do $10^{\circ} \mathrm{CIDI}$ e $10^{\circ} \mathrm{CONGIC}$

Kelli C.A.S. Smythe, Rafael de Castro Andrade (orgs.)

Sociedade Brasileira de Design da Informação - SBDI

Curitiba | Brasil | 2021
Proceedings of the $10^{\text {th }} \mathrm{CIDI}$ and $10^{\text {th }}$ CONGIC

Kelli C.A.S. Smythe, Rafael de Castro Andrade (orgs.)

Sociedade Brasileira de Design da Informação - SBDI Curitiba | Brazil | 2021 
matrículas, apenas $9,5 \%$ é de escolas privadas e 90,4\% em escolas públicas. Embora haja um crescimento de demanda, verificamos uma divergência entre o número de estudantes matriculados no ensino médio em 2019 (3.922) do número dos matriculados no ensino fundamental (11.204). Vemos uma queda das matrículas desse perfil de estudante ao longo dos patamares, denotando uma aparente dificuldade de continuar os estudos. No Brasil, essa transição do ensino fundamental para ensino médio ou da $5^{\mathrm{a}}$ para $6^{\mathrm{a}}$ série (casos específicos de Pernambuco), implica na maioria das vezes na mudança de escola da rede municipal para a rede estadual de ensino, o que aparentemente impacta nas desistências. De acordo com dados do BID em análise do censo escolar de Pernambuco em 2019, o abandono de PCDs é maior, da $5^{\mathrm{a}}$ para a 6 a série (26\% PCDs/ $8 \%$ NÃO PCDS) e da $9^{a}$ série para o $1^{\circ}$ ano do Ensino Médio (48\% PCD/ 12\% NÃO PCDs).

No ano de 2020, a Secretaria de Educação e Esportes (SEE) do Governo do Estado de Pernambuco, em parceria com o Banco Interamericano de Desenvolvimento (BID), realizou uma implantação controlada de um novo sistema de matrículas na Regional Agreste Centro Norte (GRE Caruaru). Nesse novo processo, o algoritmo de atribuição de vagas deu condições de prioridade para as opções apontadas de vagas a estudantes com necessidades especiais, sendo essa informação uma oportunidade para realização de um experimento com técnicas de economia comportamental. Dentro dos estudos sobre a tomada de decisão, a arquitetura da escolha (nudging) interage com o contexto de tomada de decisões, visando dar um pequeno "empurrão" para o comportamento preferível. Segundo Richard Thaler e Cass Sunstein (2008), os nudges são cutucadas ou orientações, que influenciam o comportamento das pessoas de maneira previsível, sem proibir nenhuma opção, nem mudar significativamente seus incentivos econômicos. Para ser considerada uma mera cutucada ou orientação, uma intervenção deve ser fácil e barata de realizar, não sendo ordens. Curiosamente, há uma grande aproximação dessas técnicas da teoria e prática do design, sobretudo em áreas como design emocional e usabilidade, envolvendo estratégias para gerar confiança, incentivar cliques ou gatilhos para compra.

O experimento proposto, portanto, partiu o objetivo de enviar nudges sobre a matrícula, para isso utilizamos a abordagem do design thinking para construir e testar esses estímulos e, posteriormente, executar o experimento de envio para famílias de estudantes com deficiência da GRE Caruaru, com o objetivo de avaliar possíveis efeitos sobre a continuidade nos estudos.

\section{Processo de design}

Para construir o planejamento de estímulos e seus conteúdos, utilizaremos um misto de metodologias a partir da abordagem do design thinking, um método de procedimento abdutivo orientado a criação de hipóteses, verificação e aprendizagem, aderente ao pensamento orientado à inovação. O olhar para o "jeito de interagir com problemas" foi nomeado no artigo "Wicked Problems in Design Thinking" (1992) onde o autor Richard Buchaman aponta a metodologia do design aplicado a serviços, para o design de processos, com o pensamento holístico focado em pessoas. Desde então, instituições como a britânica Design Council, vem 
disseminando essas práticas a partir de 2004 em diversos tipos de projetos, apresentando seu "duplo diamante", entre momentos de divergência e convergência, envolvendo

experimentações voltadas para gerar alternativas antes de definir qual caminho seguir. Abaixo podemos ver a evolução do diamante duplo em 4 etapas conforme a publicação de 2019 , "Beyond Net Zero: a systemic design approach", onde o Design Council atualiza o framework:

- Explorar: Entender o que está acontecendo, determinar fatores raiz do problema, mapear boas práticas existentes, recursos que podemos reutilizar ou desenvolver, além de gerar uma visão sobre o futuro do tema.

- Reformular: Enxergar o desafio a partir de diferentes perspectivas, identificando oportunidades e barreiras, apontando caminhos para novas ideias.

- Criar: Desenvolver uma série de diferentes ações e ideias que podem se conectar com outras intervenções e ajudar a gerar um movimento em direção a um objetivo maior, priorizando e especificando caminhos.

- Catalisar: Prototipar e testar, pensar como as coisas vão evoluir a partir disso, criar métricas e histórias para fomentar um caminho para a implantação e evolução.

Seguimos essas etapas envolvendo métodos específicos para cada uma. No caso desse experimento, temos uma situação particular, uma vez que o uso de motivações através de mensagens de texto já era um "ponto fixo" a ser implementado e avaliado, deixando a fase de reformulação e criação mais restritas. Para um processo de design, é natural trazer um olhar sistêmico sobre o desafio de forma a olhar para hipóteses existentes com certo questionamento, no caso houve certa preocupação de não conseguir explorar o suficiente e estarmos muito presos ao uso de mensagens, sob o risco de não encontrar caminhos eficientes e/ou não conseguir entender fatores relacionados ao desafio de ponto de vista mais amplo ou de outro ângulo (etapa reformular). Ainda assim, acreditamos ter exercitado essas e tivemos a oportunidade de ir além disso, pois chegamos a implantar e avaliar o que foi feito.

\section{Explorar e Reformular}

Durante o processo, a fase de entender o desafio envolveu pesquisas secundárias (dados existentes) e primárias (coleta através de entrevistas por telefone).

\section{Pesquisa Secundária}

A pesquisa secundária envolveu levantamento bibliográfico e uma busca por casos de estudo em geral, através sites de jornais, artigos, teses e dissertações, plataforma de buscas e sites institucionais.

\section{Convencimento de pessoas com deficiência}

Embora seja constatado o aumento progressivo de estudantes matriculados em regime de inclusão nas escolas públicas do Brasil, as condições para permanência são pouco favoráveis. 
É o que mostra o artigo de Kasper et al. (2008) sobre estudantes de escola pública no nível fundamental. As autoras destacam o fato do fracasso e da evasão escolar estarem diretamente ligados ao despreparo das escolas em receber e atender essas crianças. Destacamos algumas barreiras percebidas a partir disso, dentre elas: a situação das escolas públicas que apresentam ainda uma série de precariedades, e que vem sofrido com segurança, falta de aulas presenciais devido à pandemia de COVID-19. As autoras afirmam que os benefícios de estudar para pessoas com ou sem deficiência são semelhantes no sentido de integrar socialmente o estudante, que em ambiente coletivo como a escola tem experiências e convivências positivas para o seu desenvolvimento, contribuindo com a sua construção de identificação como indivíduo ativo na sociedade. Além disso, a participação em contextos inclusivos pode trazer benefícios sociais e emocionais para os estudantes com deficiência, incluindo o desenvolvimento e a manutenção de relacionamentos positivos com seus colegas, com implicações importantes para a aprendizagem da criança e seu desenvolvimento psicológico.

\section{Nudge na educação}

Sobre o uso do nudge na educação, vemos uma literatura ampla, através do compilado "Nudging and Shoving Students Toward Success", publicado na revista digital Education Next por Philip Oreopoulos. O autor trata do uso de estratégias comportamentais em diversos setores, dentre eles 126 experimentos de cutucada de baixo toque envolvendo nudges no ambiente governamental nos Estados Unidos, encontrando no grupo que recebeu o estímulo um impacto que gera um aumento de apenas $8,1 \%$ sobre a parcela do grupo de controle que não recebeu estímulos. Na sua leitura, a maioria das intervenções, portanto, gerou apenas pequenos ou nenhum efeito. Sobre questões técnicas, vemos que existe uma diferença entre nudges de baixo toque (baixo custo e baixa interferência) e de alto toque (normalmente de maior custo e maior influência). Os SMS são um dos grandes exemplos de baixo toque, enquanto podemos ilustrar os de alto toque como grupos de apoio, aconselhamento personalizado, etc. $O$ autor também traz o conceito de "empurrão", que, diferente da "cutucada" no caso da matrícula, seria diminuir o número de barreiras ao máximo como, por exemplo, já ofertar uma pré-matrícula realizada para que as famílias apenas confirmem. Ao mesmo tempo, o autor ressalta que influenciar hábitos, questões sentimentais e crenças, é bem mais complicado do que tarefas mais objetivas e definidas. No seu texto sobre a parte educacional de crianças, ele apresenta que seria mais eficiente focar nos responsáveis que estão mais abertos à "ajuda".

\section{Sobre o uso de SMS}

Em estudo sobre ensino médio no Brasil, França (2019), na sua dissertação de psicologia comportamental, pesquisou sobre como influenciar a frequência escolar através de SMS. Dentre alguns achados da sua pesquisa, a autora aponta como boas práticas:

\footnotetext{
"(a) a baixa taxa de abertura dos SMS após o sexto dia de intervenção, (b) o intervalo e a frequência das mensagens, (c) a falta de um mapeamento das causas da evasão para os adolescentes antes da pesquisa e (d) o momento do período letivo em que foi realizada a intervenção." França (2019)
} 
Na sua conclusão, ela aponta que há uma dificuldade maior em se estabelecer um padrão de frequência adequado a todos os participantes, e sugere que pesquisas futuras enviem as mensagens em dias alternados, totalizando no máximo três mensagens por semana para evitar um possível efeito de saturação. Com isso, aprendemos que as mensagens são valiosas e não devem ser usadas deliberadamente, uma boa estratégia com poucas inserções valem mais do que várias inserções não orquestradas.

Vale ressaltar que, apesar da qualidade do conteúdo ser importante, de acordo com Damgaard e Nielsen (2018), as limitações cognitivas são uma barreira grande para tomada de decisão. Possivelmente, muitos dados podem ser ignorados, esquecidos ou até causarem efeito contrário ao esperado, portanto, pode não ser a falta de motivação e sim a falta de capacidade para executar determinada tarefa. Com todo o exposto, começamos a intuir caminhos para o experimento a partir dessas informações e boas práticas.

Tabela 1: Resumo de aprendizados da fase de exploração secundária

\begin{tabular}{|c|c|c|c|}
\hline Sobre o uso de SMS & $\begin{array}{l}\text { Sobre Argumento de } \\
\text { convencimento }\end{array}$ & $\begin{array}{l}\text { Sobre técnicas de } \\
\text { nudge }\end{array}$ & $\begin{array}{l}\text { Sobre a efetividade do } \\
\text { experimento }\end{array}$ \\
\hline $\begin{array}{l}\text { Os SMS devem ser } \\
\text { enviados numa janela } \\
\text { de tempo de } 3 \text { a } 5 \\
\text { semanas com } 3 \\
\text { mensagens por } \\
\text { semana em dias } \\
\text { alternados. }\end{array}$ & $\begin{array}{l}\text { Os dados quantitativos } \\
\text { devem ser } \\
\text { contextualizados de } \\
\text { maneira simples e } \\
\text { objetiva buscando a } \\
\text { compreensão fácil. }\end{array}$ & $\begin{array}{l}\text { Um nudge de baixo } \\
\text { toque como o SMS } \\
\text { pode ter efeito nenhum } \\
\text { se posto de encontro a } \\
\text { crenças limitantes e } \\
\text { desmotivação por } \\
\text { motivos diversos }\end{array}$ & $\begin{array}{l}\text { É possível que o SMS } \\
\text { sejam enviados a } \\
\text { números inativos ou } \\
\text { reciclados se não } \\
\text { conferidos }\end{array}$ \\
\hline $\begin{array}{l}\text { O público com } \\
\text { limitações pode ao se } \\
\text { deparar com muito } \\
\text { conteúdo pode achar } \\
\text { que é complicado e } \\
\text { desistir }\end{array}$ & $\begin{array}{l}\text { Diversos dados de } \\
\text { benefício podem ser } \\
\text { utilizados como artifício } \\
\text { de apoio ao } \\
\text { convencimento . }\end{array}$ & $\begin{array}{l}\text { O experimento deve de } \\
\text { alguma maneira gerar } \\
\text { acesso direto ao minha } \\
\text { matrícula digital }\end{array}$ & $\begin{array}{l}\text { Pela multiplicidade de } \\
\text { condições humanas } \\
\text { que o macro grupo } \\
\text { PCD abriga, um } \\
\text { desengajamento é } \\
\text { possível devido a uma } \\
\text { super generalização. }\end{array}$ \\
\hline $\begin{array}{l}\text { É preciso avaliar a } \\
\text { credibilidade do banco } \\
\text { de números de } \\
\text { responsáveis. }\end{array}$ & $\begin{array}{l}\text { É necessário cautela no } \\
\text { uso das argumentações } \\
\text { buscando evitar excluir } \\
\text { um ou mais perfil } \\
\text { distinto de pessoa com } \\
\text { deficiência. }\end{array}$ & $\begin{array}{l}\text { Deveríamos considerar } \\
\text { "empurrar" ao invés de } \\
\text { cutucar, gerando } \\
\text { facilidades ou pré- } \\
\text { matrículas automáticas }\end{array}$ & $\begin{array}{l}\text { O impacto de nudges } \\
\text { de baixo toque tem se } \\
\text { mostrado baixo ou no } \\
\text { mínimo controverso a } \\
\text { depender do contexto }\end{array}$ \\
\hline
\end{tabular}

\section{Pesquisa Qualitativa e Construção de Estratégia}

Complementando o levantamento de boas práticas, realizamos uma pesquisa primária de caráter qualitativo, que teve como objetivo o aprofundamento nos fatores determinantes para desistência ou continuidade das famílias, entendendo também pelo ponto de vista da equipe escolar, como funciona o processo de orientação e recepção por parte das escolas, além das inseguranças/motivações por parte da família. O foco dessa pesquisa foi capturar e entender comportamentos e tendências através das saturações dos resultados dos seus discursos. Para 
isso foram construídos roteiros semiestruturados que permitiam a partir de tópicos, o improviso para o entendimento desses públicos em entrevistas por telefone, realizadas em novembro de 2020. Foram entrevistadas 12 famílias de estudantes PCDs e 04 pessoas da equipe escolar ou da gestão, além disso, foi feito um grupo focal com cerca de 08 pessoas de vários municípios que trabalham diretamente com o perfil de público

Tabela 2: Resumo de aprendizados da fase de exploração primária

\begin{tabular}{|c|c|}
\hline Sobre o uso de SMS & $\begin{array}{l}\text { Sobre Argumento de } \\
\text { convencimento }\end{array}$ \\
\hline $\begin{array}{l}\text { A comunicação da } \\
\text { escola com os } \\
\text { responsáveis e } \\
\text { estudantes se dá } \\
\text { principalmente por } \\
\text { ligação para o celular e } \\
\text { por mensagens no } \\
\text { WhatsApp }\end{array}$ & $\begin{array}{l}\text { É interessante } \\
\text { esclarecer aos pais que } \\
\text { a escola não é apenas } \\
\text { espaço para apreensão } \\
\text { de conteúdo } \\
\text { pedagógico, mas lugar } \\
\text { de convivência social e } \\
\text { as crianças com } \\
\text { dificuldades mentais } \\
\text { podem se beneficiar da } \\
\text { ida à escola }\end{array}$ \\
\hline
\end{tabular}

\section{Sobre técnicas de nudge}

É preciso diminuir os pontos de atrito do processo de matrícula, seja através de listas de escolas mais dirigidas à necessidade do público ou facilitando/incentivando a declaração de PCD para que tenham preferência de fato

Precisamos ter cuidado ao usar termos para se referir à $\mathrm{PCDs}$ pois nem todos se consideram ou gostam de termos como especiais ou deficientes

Há uma desinformação sobre o atendimento de profissionais especializados na rede estadual. Muitas vezes houve uma luta dos responsáveis pela contratação de profissionais na municipal, gerando receio de uma possível perda de algo já conquistado
A prova social através estudantes PCD que continuar e tem tido sucesso podem ser caminhos eficientes

Temos que ter um cuidado com outras deficiências mentais pois podem estar frequentando escolas sem atendimento especializado e não estarem progredindo nem sendo percebidos com a devida importância de outras famílias com

\section{Sobre a efetividade do} experimento

\author{
Há dificuldades \\ estruturais sobre as \\ mudanças para $o$ \\ ensino médio que \\ precisam ser pensadas \\ sob o risco de \\ estudantes após \\ matrícula desistirem \\ (Transporte, falta de \\ suporte técnico, muitos \\ professores, falta dos \\ colegas de \\ sala/acolhimento)
}
Não há um banco de dados bem estruturado e integrado (município- estado). Os professores possuem os telefones, mas não é repassado tais atualizações para o banco
Há evasão escolar antes do processo de transição do municipal para o estadual devido às barreiras enfrentadas nas escolas que frequentam. Ter suporte psicológico e/ou de associações civis auxilia na busca por direitos e a se manter na escola

A partir desse acumulado de conhecimentos, foi formulada uma série de hipóteses que nos ajudaram a construir um primeiro planejamento para teste junto a grupos de famílias e comunidade escolar. Ressaltamos a inserção das mensagens de voz pontualmente, para buscar atingir famílias que tenham dificuldade de acesso a mensagens de texto, tanto por não saberem ler, como por também apresentarem algum tipo de deficiência, ou ainda, por não terem uma versatilidade tecnológica não sabendo/tendo o hábito de acessar. 


\section{Criar e Catalisar (estratégia de estímulos)}

Devido ao experimento ter premissas bem estabelecidas referente ao uso de mensagens de texto (SMS), o processo de criação foi dirigido a isso. Ainda assim, no processo de divergência do design, outros caminhos naturalmente surgiram, como usar mensagens via whatsapp ao invés de SMS, mas não foi tecnicamente viável através das plataformas disponíveis no mercado, além disso, inserimos o torpedo de voz que funciona com uma ligação gravada automática, tentando viabilizar o acesso ao público PCD. Além dessas questões operacionais, os conteúdos das mensagens foram criados seguindo os princípios de estratégia definidos, conforme levantamento de conteúdos relacionados disponíveis: como leis e informações existentes de outros estudos e etc. Ressaltamos que o caráter colaborativo do processo de design envolvendo públicos fundamentais da comunidade escolar e sobretudo quem iria receber os estímulos, se deu através da apresentação de propostas em testes/avaliações, para facilitar a participação por se tratar de um tema sofisticado para o público.

Figura 1: Planejamento de estímulos para experimento

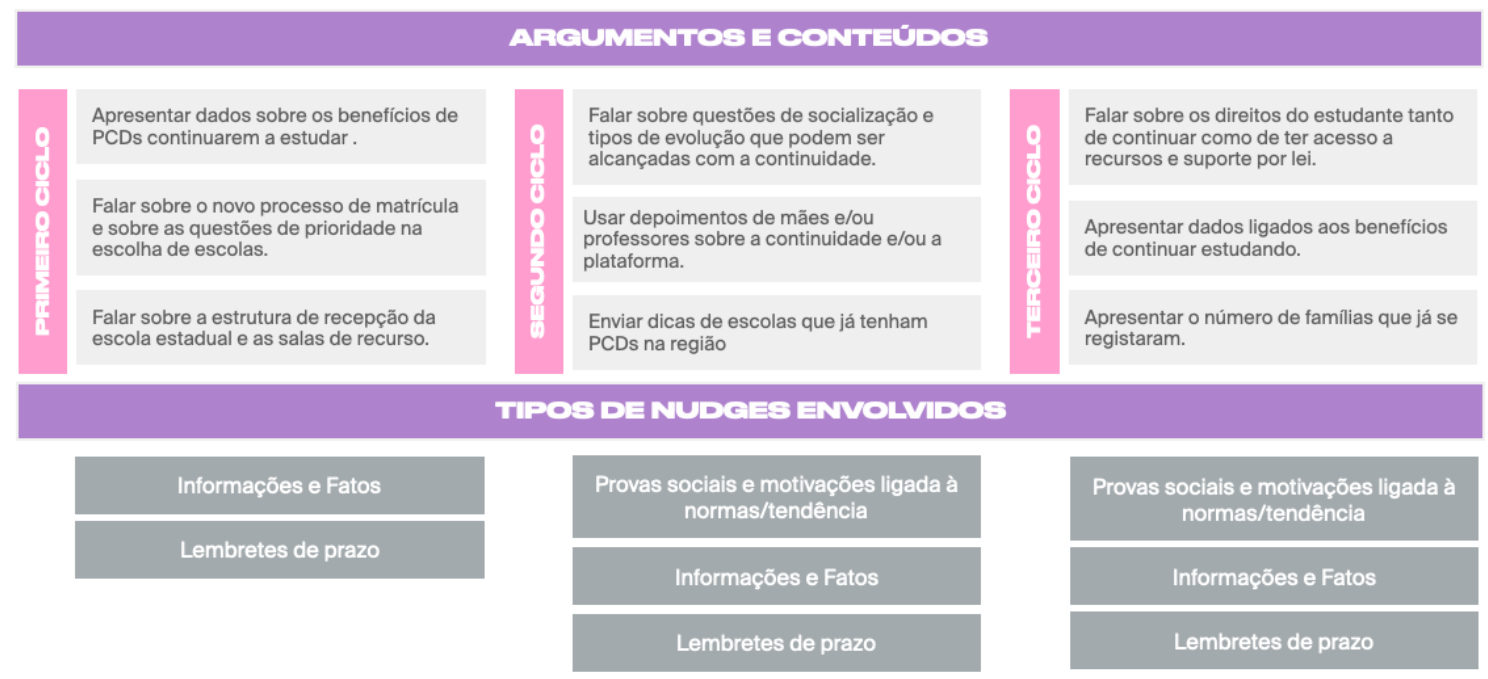

\section{Design da Informação}

A preocupação com o caráter do design da informação dos estímulos foi um desafio devido a restritividade das mensagens de texto. A partir de Mijksenaar (2007), que apresenta uma adaptação de alguns princípios visuais para design, vemos essas limitações do SMS e da mensagem de voz. Elas não contam com cores, ilustrações, escolhas tipográficas, contam com alguns recursos mapeados pelo autor como Hierarquia (posições no texto e cronologia das mensagens), atributos do texto como CAIXA ALTA, sinais (!!), sendo ainda assim limitadas. Com isso, refletimos que para além da forma, contamos com o conteúdo. Entender isso em detalhes exige uma aproximação da linguística, afinal a interface textual ou discursiva tem a sua especificidade. Mikhail Bakhtin, dito como o filósofo do diálogo, apresenta que um enunciado é um movimento dialógico, se origina de alguém e se destina a alguém, mesmo que esses interlocutores estejam implícitos, isso afeta a percepção tanto quanto o contexto social 
desses interlocutores. Para Bakhtin (2003), tudo isso dá forma e estilo à enunciação, sendo o centro de toda enunciação exterior, é o contexto do meio social que envolve o indivíduo. Dessa forma, entendemos que o conteúdo textual é também forma, e é também interface. $E$ foi com essa preocupação que entendemos que o posicionamento do emissor das mensagens de estímulo dificilmente não seria percebido como Governo do Estado, entendendo que essa posição também permitiu ter credibilidade ao falar do assunto em questão. Junto a isso construímos um "tom de voz" direto e, ao mesmo tempo, engajador, buscamos denotar uma preocupação real, gerada através da transparência sobre direitos, leis, gerando estímulos para cobrança do próprio governo, mas não só isso, tendo uma preocupação em usar palavras específicas, objetivas e concretas conforme percepções obtidas nas pesquisas. Usamos palavras fortes como "PREFERÊNCIA", "DIREITO", "EMPREGO". Também foi pensada uma narrativa, onde as mensagens eram enviadas seguindo uma lógica, distribuindo as estratégias de nudge como dados no começo, prova social no "meio" (exemplo de outras pessoas) e escassez de tempo (prazo de matrículas) mais ao final.

\section{Avaliação através de testes}

Durante 01 semana enviamos 01 ciclo da mensagem dos 03 ciclos idealizados para 03 grupos mistos (famílias e especialistas), de forma a ter todas as mensagens enviadas e passíveis de feedback. Esse protótipo nos ajudou a fazer refinamentos de conteúdo e de estratégia. Através dessa avaliação nesse microuniverso, já conseguimos ver que tanto parte do público não notou o SMS, mas notou a mensagem de voz, bem como as mensagens de voz serviram como um "gatilho" para o acesso do SMS. Ainda sim, foi percebido que nem todos ouviram as mensagens de voz de cerca de 20 s até o final.

Sobre os conteúdos e linguagem, os retornos foram muito positivos, participantes que leram, conseguiram lembrar das mensagens e ressaltaram mensagens ligadas a legislação e informações dos seus direitos. Vemos algumas questões de nomenclatura podem diminuir barreiras, como a diferença de assistência entre município e estado, usando palavras-chave como "acompanhamento" para o que o estado chama de "salas de recurso", apesar de não ter um profissional para auxiliar o estudante durante a aula (salvo caso intérpretes) pode ajudar a quebrar uma primeira barreira.

Outro feedback importante desse processo foi por parte da equipe escolar que nos trouxe que no processo de transição os próprios diretores de escolas estaduais ficam preocupados em como receber esses estudantes e muitas vezes não são receptivos e não recebem um apoio preparatório efetivo. Esse é o ambiente de complexidade que o experimento enfrenta, precisamos, portanto, ter plena consciência das consequências e dificuldades da operacionalização do experimento. Com tudo isso, chegamos à seguinte proposta: 
Figura 2: Ciclo de mensagens de texto e voz para experimento

\begin{tabular}{|c|c|c|c|}
\hline & & 19/12 (sabado) & $\begin{array}{l}\text { TORPEDO DE VOZ - 19/12 } \\
\text { (sábado) }\end{array}$ \\
\hline & & $\begin{array}{l}\text { MinhaMatricula PE: A matricula } \\
\text { nas escolas estaduais já } \\
\text { começou! Se vocế é } \\
\text { responsável por estudante com } \\
\text { necessidade especifica, vamos } \\
\text { enviar dicas para você. }\end{array}$ & $\begin{array}{l}\text { Mensagem da nova matricula do estado: Sabia } \\
\text { que nova matrícula pode ser feita pelo celular } \\
\text { e que estudantes com alguma necessidade } \\
\text { especfifica têm PREFERENCIA na hora de } \\
\text { escolher as escolas? Para fazer a inscriçäo } \\
\text { basta acessar www.minhamatricula.pe.gov.br }\end{array}$ \\
\hline E1/12 (segunda) & 2a/12 (quarta) & 25/12 (sexta) & $\begin{array}{c}\text { TORPEDO DE VOZ - aE/1a } \\
\text { (sábado) }\end{array}$ \\
\hline $\begin{array}{l}\text { MinhaMatricula: Nas escolas, } 0 \\
\text { estudante pode requerer } \\
\text { intérprete e professor } \\
\text { especializado. Tem também as } \\
\text { salas de recurso para } \\
\text { complementar as aulas. SEU } \\
\text { DiRETOT. Para mais informaçêes, } \\
\text { acesse https://abre.ail/bQhN }\end{array}$ & $\begin{array}{l}\text { MinhaMatricula: Separamos } \\
\text { algumas escolas que já } \\
\text { atendem estudantes com } \\
\text { necessidades especificas, você } \\
\text { pode achar elas e outras no site } \\
\text { da matrícula, conheça aqui } \\
\text { XXXXXXXX }\end{array}$ & $\begin{array}{l}\text { MinhaMatricula: Ensino médio é } \\
\text { mais emprego. Jovens com } \\
\text { deficiência em } \\
\text { PE que CONTINUARAM a } \\
\text { estudar têm } 50 \% \text { mais chances } \\
\text { de emprego de quem NÃ̄o } \\
\text { continuou. }\end{array}$ & $\begin{array}{l}\text { Mensagem da nova matricula do estado: Você } \\
\text { recebeu no seu celular algumas mensagens de } \\
\text { SMS com informaçōes e dicas sobre o novo } \\
\text { processo de matricula da rede estadual, o } \\
\text { estudante com necessidades especificastem } \\
\text { direito a professores especializados, você poderá } \\
\text { solicitar após a matrícula. Quer saber mais? } \\
\text { Acesse o wWW.minhamatricula.pe.gov.br ou fale } \\
\text { com a sua escola de origem. }\end{array}$ \\
\hline ag/1a (segunda) & ag/1a (terça) & so/12 (quarta) & $\begin{array}{l}\text { TORPEDO DE VOZ - sO/12 } \\
\text { (quarta) }\end{array}$ \\
\hline $\begin{array}{l}\text { MinhaMatricula: Todo jovem } \\
\text { com deficiência tem DIREITO } \\
\text { a escola e a atendimento } \\
\text { educacional especializado. } \\
\text { Saiba mais em: https:/l } \\
\text { abre.ai/bQhN }\end{array}$ & $\begin{array}{l}\text { MinhaMatricula: Mais escola, } \\
\text { mais autonomia. Os estudantes } \\
\text { que passam mais tempo nas } \\
\text { escolas têm uma vida mais } \\
\text { independente. }\end{array}$ & $\begin{array}{l}\text { MinhaMatricula: Muitos } \\
\text { estudantes com deficiência já } \\
\text { se inscreveram e vão continuar } \\
\text { os estudos em 2021. Nāo perca } \\
\text { a oportunidade. }\end{array}$ & $\begin{array}{l}\text { Mensagem da nova matrícula do estado: } 0 \\
\text { prazo de inscrição na plataforma Minha } \\
\text { Matrícula termina hoje. Se você ainda realizou } \\
\text { a matricula do estudante, ainda dá tempo. } \\
\text { Mais estudo é mais autonomia para estudante, } \\
\text { vai lá no www.minhamatricula.pe.gov.br }\end{array}$ \\
\hline
\end{tabular}

\section{Implantar e Avaliar: Experimento Nudge}

Para realização do experimento utilizamos a base de dados disponibilizada pela Secretaria de Educação e Esportes do Governo de Pernambuco, além de consultas a atores das secretarias municipais para conseguir dados de telefone validos de famílias com PCDs. Conseguimos uma base qualificada de 115 estudantes com deficiência. Foi realizado sorteio através do software "Stata" para dividir os 115 estudantes com deficiência em 58 estudantes do grupo de tratamento (receberam os estímulos) e 57 estudantes do grupo de controle (não receberam estímulos). A partir disso foram enviadas as mensagens durante o período de matrícula do ano de 2020. Foram 05 semanas ( $3+2$ semanas extras) de estímulo, 48 (das 58 ) famílias "atingidas" e estimuladas (telefones do responsável e/ou do estudante) e um média de 15 estímulos no total por família. Apesar dos números interessantes, durante esse processo não sabemos como as mensagens foram recebidas ou se foram capazes de gerar algum tipo de efeito, por isso, após o período foi feita uma pesquisa quantitativa para avaliar esse experimento e entender possíveis efeitos.

O processo de avaliação quantitativo não será narrado em detalhes por fugir ao objetivo deste estudo. Através dessa coleta de dados, identificamos um aumento do número de pessoas que declararam se matricular no grupo que recebeu os estímulos em $2,76 \%$, porém não conseguimos afirmar estatisticamente, devido ao baixo número de respostas a pesquisa 
(64 de 107 estudantes pesquisáveis, uma consequência da precariedade da base de dados disponível para o experimento). Dentre algumas limitações e barreiras que dificultaram avaliação do experimento:

- Precariedade de dados: a desatualização do banco de dados com a presença de números inexistentes, números que não pertenciam ao estudante/ responsável e estudantes erroneamente colocados como PCD (26,56\% dos respondentes).

- Foi percebido um maior desinteresse na matricula devido à pandemia de SARS-CoV-2 (COVID-19) que teve um impacto negativo no sistema educacional como um todo.

Ainda sim, observamos que:

- Como descobriram o período de matrículas: quando perguntados sobre como descobriram o período de matrículas os respondentes afirmaram em sua maioria que foi indo presencialmente nas escolas (48\%), em segundo lugar (33\%) afirmam ter recebido mensagens da escola/equipe escolar, os SMS ficaram apenas com $1 \%$, aqui apontamos a ambiguidade da compreensão do público sobre diferenciar uma coisa de outra, inclusive ressaltamos, que no mesmo período estava acontecendo um envio de mensagens da equipe escolar pelo aplicativo de mensagens WhatsApp, que não seguiram o protocolo/estratégia de nudge, mas que os comunicavam sobre a matrícula.

- Sobre o recebimento dos estímulos: apesar desse dado, $31 \%$ dos participantes declararam ter recebido mensagem no celular ou ligação sobre a matrícula, desses $28 \%$ foi apenas o SMS. Nesses resultados estão incluídos perfis do grupo de controle, que não receberam nudge, mas que aparentemente se confundiram com as mensagens da escola. Do grupo que recebeu nudge, ninguém teve problemas para entender o conteúdo das mensagens, enquanto no grupo de controle $33 \%$ apresentou alguma dificuldade, demonstrando a diferença de um processo mais estruturado como o do experimento em relação às informações vindas da escola.

- Sobre o efeito dos nudges: todos os entrevistados do grupo que receberam nudge (tratamento) afirmaram ser importante (36\%) ou muito importante $(64 \%)$ o recebimento das mensagens para tomada de decisão sobre matrícula. Para o grande grupo (controle + tratamento), 91\% acham importante receber mensagens sobre a matrícula, em formato de Whatsapp (37\%) ou ligação telefônica (23\%), enquanto o SMS (6\%) e SMS + Ligação (8\%). Mostrando uma predileção por formatos associados a voz e a popularidade/familiaridade com o Whatsapp.

Também foram observadas questões específicas sobre o baixo engajamento na continuidade de estudantes do perfil EJA (ensino de jovens e adultos) que tendiam a não continuar no processo de transição, por já estarem numa série defasada e com menor estímulo e uma maior dificuldade de estudantes de zona rural, estes, conforme informações coletadas, possuem uma maior dificuldade na transição, já que existe um número menor de 
disponibilidade de escolas estaduais (acima do 10 ano) nessas áreas, obrigando o estudante com necessidades especiais a fazer um deslocamento maior. Esses são desestímulos que precisam de estratégias mais dirigidas para mitigação.

\section{Conclusões}

Durante todo o processo de construção e experimentação dos nudges a abordagem de design associada aos princípios da economia comportamental se mostrou uma combinação curiosamente interessante. As pesquisas e aplicações que observamos na literatura apresentam contextos muito diferentes do interior de Pernambuco, e, especialmente, do público estudantes com algum tipo de deficiência. Nosso contexto é extremamente complexo e cheio de adversidades tanto para execução do experimento como para motivação das famílias. O nosso processo de design identificou que provavelmente o "cutucão" (SMS) seria pouco perante tantas adversidades. Assim, adicionamos os torpedos de voz, argumentos mais dirigidos que não seriam possíveis sem a pesquisa, além de trazer outras hipóteses futuras como "cutucar" os professores da escola atual dos estudantes para que eles fossem um braço complementar de convencimento. Vimos que apesar do desafio precisar de estratégias e intervenções mais aprofundadas, o ponto de vista da economia comportamental trouxe um olhar mais pragmático, voltado para através de intervenções objetivas e focadas (estímulos via mensagens). Vemos que buscar diferenças percentuais quando pensamos em uma massa de pessoas, é uma estratégia interessante, sendo um recurso voltado para foco no viável a curto prazo, como um primeiro passo.

Do ponto de vista do design da informação das mensagens, não foi feita uma análise de recepção das mensagens. Foi notável, contudo, a grande carência de informação sobre direitos e sobre benefícios indiretos da continuidade dos estudos, além da oportunidade de através de conteúdo relevante e uma sequência de mensagens bem encadeadas, potencializar os estímulos. Recomendamos futuras avaliações com uso de "emojis" (a depender da temática), bem como outros recursos de visuais e sonoros através de canais com mais recursos (Whatsapp), sempre mantendo a objetividade. Sugerimos também um cuidado com o tom de voz no sentido de transparecer sobre quem é esse interlocutor e o que está implícito na mensagem.

Ressaltamos aprendizados sobre as estratégias operacionais de nudge, recomendando um maior cuidado com a disponibilidade de banco de dados e seu tratamento, bem como processos técnicos de feedback dos participantes para continuar a receber ou não as mensagens. Também percebemos que envio de mensagens em dia alternados, não gerou incômodos aos participantes. No geral é uma estratégia promissora que precisa ser experimentada para entender onde pode fazer maior diferença com as premissas de escala e baixo custo. Sendo esse caso de PCDs da GRE Caruaru, um caso que aparentemente precisa de mais "empurrões" (como a matrícula automática dos estudantes, pulando uma etapa burocrática) associados a algumas mudanças estruturais e não apenas "cutucões".

Ressaltamos que mesmo com incentivo para realizarem a matrícula de PCDs, não há garantias 
de que o mesmo permaneça ao longo do tempo. Acreditamos que num contexto de problema complexo como esse, achar saídas e/ou gerar alternativas não solucionará o problema por completo, mas pode sensibilizar os atores envolvidos para a partir do experimento gerar outras consequências. A lei de inclusão nacional em 2015 e avanços tecnológicos para ensino são perspectivas positivas diante desse problema complexo, tendo o design e a economia comportamental muito a contribuir.

\section{Referências}

Bakhtin, M. (2003). Estética da criação verbal. 4a Edição. São Paulo: Martins Fontes

Censo da Educação Básica (2019) Resumo técnico do estado de Pernambuco censo daeducação básica. INEP. Disponível em:

<https://download.inep.gov.br/publicacoes/institucionais/estatisticas_e_indicadores/resumo_t ecnico_do_estado_de_pernambuco_censo_da_educacao_basica_2019.pdf>

Damgaard, M. e Nielsen, H. (2018) Nudging in education. Economics of Education Review Volume 64, June 2018, Pages 313-342.

Design Council (2019). Beyond Net Zero: a systemic design approach. Disponível em: $<$ https://www.designcouncil.org.uk/resources/guide/beyond-net-zero-systemic-designapproach\#: :text=The\%20Systemic\%20Design\%20Framework\%2C\%20launched,at $\% 20$ the $\% 20$ heart\%20of\%20design.>

França, Bruna. (2019). O envio de mensagens de texto como ferramenta para aumentar a frequência escolar de adolescentes do Ensino Médio. Dissertação (Mestrado em Ciências do Comportamento), Universidade de Brasília, Brasília.

Kasper, Andrea de Aguiar et al. (2008). Alunos com deficiência matriculados em escolas públicas de nível fundamental: algumas considerações. Educ. rev. [online]. 2008, n.31. http://dx.doi.org/10.1590/S0104-40602008000100014.

Mijksenaar, Paul. Visual function: an introduction to information design. Rotterdam: 010 Publishers, 1997.

Oreopoulos, Philip. Nudging and Shoving Students Toward Success. Educationnext Spring Vol. 21, No. 2. 2020. Disponível em: <https://www.educationnext.org/nudging-shoving-studentstoward-success-what-research-shows-promise-limitations-behavioral-science-education/>"

Thaler, R. e Sunstein C. (2008). Nudge: o empurrão para escolha certa. Tradução: Marcello Lino. Editora: Elsevier

\section{Sobre o(a/s) autor(a/es)}

J. Cézar Cavalcanti Rocha, Mestre Design, UFPE, Brasil <cezarcavalcanti@gmail.com> Débora Vasconcellos, Doutoranda Sociologia, UFPE, Brasil

<debora.vasconcellos15@gmail.com>

Stéphanie Gomes, Doutoranda Sociologia, UFPE, Brasil <stephanie.gomes@gmail.com > 